\title{
Ontogenesis and architectural analysis of Myricaria bracteata Royal in East Kazakhstan
}

\author{
Alexey Astashenkov ${ }^{1 *}$, and Elena Lyakh $^{1}$ \\ ${ }^{1} \mathrm{PhD}$ of Biology, Central Siberian Botanical Garden Siberian Branch RAS, 630090 Novosibirsk, \\ Russia
}

\begin{abstract}
The article presents research of Myricaria bracteata shrub ontogenesis and architecture under East Kazakhstan conditions. The study revealed that the specimen ontogenesis is complete and includes two phases of development: a primary shoot and a primary bush. The adult speciment structure is built due to consistent development of perennial orthotropic/skewed orthotropic skeletal axes was forming from the resting buds. Annually dying lateral vegetative and generative shoots are formed of branching resting buds located on these axes. The architectural unit of M. bracteata consists of 5 categories of axes: 1 - perennial orthotropic, 2 perennial lateral skewed orthotropic, 3 - annual lateral generative bracteose, 4 - annual lateral generative frondose, 5 - annual lateral vegetative ones.
\end{abstract}

\section{Introduction}

Myricaria bracteata Royle is a fluviaphyte [1] which is a pioneer vegetation compound at the succession initial stages of river sand floodplains and pebble overgrowing [2]. Investigations of ontogenesis and growth form make it possible to identify mechanisms of speciment morphological adaptation and their stable existence in changing environment [3]. Structural analysis allows determining the polymerization degree and sprout system hierarchical subordination in a general plant design, which is of great importance in studying evolution of the life form architecture [4]. Pioneer shrubs having deterministic growth of monopodial axes with lateral inflorescences are not practically researched in this attitude. The work objective is to study M. bracteata ontomorphogenesis and architectural organization under East Kazakhstan conditions.

\section{Materials and methods}

M. bracteata is a $2.0-2.5 \mathrm{~m}$ high geoxyl shrub. It is spread in Central Asia. The typical habitats of $\mathrm{M}$. bracteata are confined to stony-sandy banks of mountain rivers, pebbles, dried mountain stream and river beds. It often grows along mountain and gorge slopes upto $2500 \mathrm{~m}$ height above sea level [5]. In frames of its range it grows in small groups,

\footnotetext{
* Corresponding author: astal@bk.ru
} 
sometimes forms extensive overgrowth, and is often part of floodplain poplar (Populus laurifolia) forests and willow (Salix sp.) riverine tree stands.

The field research was carried on in East Kazakhstan, the material was collected on the Kokterek River pebble stones of the Tarbagatai ridge southern macroslope. While studying ontogenesis, the concept of the ontogenesis discrete description [6,7] was used, the morphogenesis phases were determined according to the characteristic proposed by O.V. Smirnova with co-authors [8]. The shoot system structural organization is described based on the ideas by I.G. Serebryakov [3], M.T. Mazurenko, and A.P. Khokhryakov [9]. The architectural analysis was done according to the concept by D. Barthélém et Y. Caraglio [4].

\section{Results and discussion}

The M. bracteata fruit is an aciniform unilocular fruitcase opened to the base with valves. Seed sprouting is aboveground and outbreaks in late July - early August [10]. A sprout is a bicotyledonous plant of 1.0-1.5 cm high with pronounced hypocotyl. In the same year, after cotyledon withering, the specimets become juvenile.

The primary shoot of a juvenile sample grows monopodially. Narrow-lanceolate green leaves are unfurled on its orthotropic elongated axis. About 50-60 green leaves are formed throughout the growing season. Lateral buds are laid in all leaf axils. Buds formed in the cotyledons and methamer nodes, multiple of 7 , differ from the others in larger sizes and high primordia number (they are always more by 5-10 phytomers).

In the juvenile state, specimens have different variants of branching.

1) Branching shoots are 1-2 sylleptic, they unfurled from one or two buds embedded in cotyledons. Lateral shoots of the II order are orthotropic, their length reaches $2.0-4.0 \mathrm{~cm}$. The lateral shoot consists of a brachytic basal part bearing 7 short metameres with cataphylls, and a long one bearing true green leaves

2) In a case of a terminal bud damage of a primary shoot, a series of higher order ortho/anisotropic lateral shoots (III-IV order) develop on the II order shoots. By the late vegetation season, the most shoots die off. Only lignified parts of the second-order lateral shoots preserve. By the close of year, the initial sprout dies off forming a stub.

Thus, the lateral shoot development results in a bush formation. Plants in the first year move into the primary bunch phase, which lasts to the ontogenesis final. Underdeveloped ephemeral shoots (ES) are unfurled every 6-7 metamers on lateral shoots, as well as on the main ones. In the rest alae, the buds are poor developed or not formed at all.

The plants go into an immature ontogenetic state in the seconf year. Individuals grow simpodially. 2 leading orthotropic shoots or formation shoots (FS) are unfurled on buds in the basal part of last year shoots. Their apical meristem dies off at the close of year, the axes persist and become perennial. Emerging FSs have orthotropic growth direction, they reaches $20.0 \mathrm{~cm}$ length, and 0.2-0.4 cm diameter. Each FS consists of 45-50 long metamers. ESs are formed along axis every 5-7 nodes. The rest buds are not realized and branching. By the late vegetation season, the most FS axis is lignified forming the first skeletal axes (SA) of the shrub. The buds located in the FS basal shortened part become dormant and start branching as well. Overgrowing the lower part of shoots and the root basal part lead to xylopodium formation. The main root increases in size upto $20 \mathrm{~cm}$, branches upto the III order.

The plants pass to a virginile state on the third-fourth year. The bush height reaches 40 $\mathrm{cm}$. In the speciment structure, there are perennial two SAs and young 1-2 FS(s) arosed of dormant xylopodium buds. The emerging FSs grow monopodially during the vegetation season, their terminal bud dies off at the close of year. The remained axes enter the bush perennial base and become SAs. Buds are branching along the whole above-ground part of 
each SA. ESs are mainly formed of buds of nodes multiple 5-7 methamers, their number varies from 2 to 7 . Usually, vegetative ephemeral shoots are unfurled of a maternal bud, the filial buds remain dormant and branch out afterwards. Ephemeral and underdeveloped vegetative shoots of 5-8 $\mathrm{cm}$ high are often unfurled of xylopodium resting buds, which are deepen in ground. The main root thickens to $3-4 \mathrm{~cm}$ in the basal part. The state duration is no more than 3 years.

On the sixth-seventh year, specimens bloom and pass into a young generative state. Their structure includes SAs developed in the virginal state of 70,0-100,0 cm height, the basal part of which does not exceed $1.0 \mathrm{~cm}$ in diameter. Skeletal axes, formed in the immature state, die off completely. Young FSs (1-3 axes) are unfurled of large branching dormant xylopodium buds. These shoots branch over their entire ES axis during a year. Only some axis buds are not realized, and remain dormant and branch. A FS ends with a vegetative bud. The FSs appeared during a year are lignified, become SAs, and enter the bush perennial structure.

Generative organs are laid a year before flowering in large proleptic filial lateral buds preserved on SAs. They usually develop of the node buds of metamers, multiples of 7-9. Generative shoots with a spicate open bracteose inflorescence (Bi) (a blossom cluster) are developed on each SA. All flowering shoots are annuals and after flowering completely die off. The total number of flower-bearing shoots on a SA varies from 5 to 20, their length does not exceed 7.0-10.0 cm, the most part is a blossom cluster itself reaching $6.0-8.0 \mathrm{~cm}$.

Under this conditions, the ability of SA axillary buds to branch intensively can lead to their simultaneous realization forming a "wisp" consisting of closely spaced 3-5 ESs. Xylopodium increases in size to $4.0 \mathrm{~cm}$ in diameter. The main root is twisted fusiformly. This state duration does not exceed 5 years.

Mature generative specimens are plants of above $2.0 \mathrm{~m}$ height reaching $1.2-1.5 \mathrm{~m}$ in diameter. The bush aboveground structure consists of functionally distinguised shoots and axes of different age and order. New axes emerging leads to the bush spread, while peripheral axes lie flat.

According to the position in space and time of appearing in the bush structure, there are two FS types determined SAs: 1) orthotropic ones formed of resting xylopodium buds; 2) lateral skewed orthotropic ones formed of dormant buds in the middle part of an orthotropic SA.

The first FS type development is similar to that described above. The difference is only in sizes (a shoot height is 120.0-240 cm). During the first year, only ESs are formed on the shoot. The FS terminal bud always remains vegetative one and dries together with ES in the late growing season. The long axis is preserved and becomes perennial. The next year, generative shoots and new ESs are formed of the lateral buds remaining on the axis. Such $\mathrm{SA}$ in the bush structure exists 10 years at the mostand reaches $1.8 \mathrm{~cm}$ diameter. The orthotropic SA number is 15-20 in the adult bush. The axis buds do not all unfurled into shoots, some of them remain dormant throughout the growing season. Such rhythm of bud development and functioning leads to their branching and increasing number for future generations. For example, it has been revealed that buds of metamers, multiples of 4 , remain dormant on an axis of 5 year old.

FS of the second type is isolated of a leading lateral vegetative shoot, which arose from a dormant bud in the orthotropic SA mid part. Its development also ends with the terminal bud death. The lateral FS is lignified, becomes perennial, and enters the orthotropic SA structure. No more 2-3 lateral SA can be formed on an orthotropic SA during its whole functioning period. The lateral axes are in a general structure until all orthotropic SA dying. In rare cases, they die. As a result of mesotonic branching, lateral SAs build up a perennial SA system vertically and fill the space of the bush middle part. 
In this condition, two types of generative shoots with bracteose (Bi) (with cataphylls) and frondose (Fi) inflorescences (with real green leaves and lateral ESs) are identified on $\mathrm{SA}$, which appearance differs in time. The Bi (spring) generative shoots unfurl first, then Fi (summer) ones appear. Bi shoots are formed annually from branching filial buds along the whole axis; Fi - neither annually, nor on every axis in the distal part of large 1-3 filial or maternal buds. Bi length does not exceed $15 \mathrm{~cm}$; Fi shoot length is $20-40 \mathrm{~cm}$, the inflorescence ranges from 7 to $25 \mathrm{~cm}$. After fruiting, Bi dies completely, Fi shoot axis remains for some time in a form of a long dry whip, which breaks off gradually.

Xylopodium grows to $25 \mathrm{~cm}$ and represents the bush basal part with a large number of branching resting buds. The authors have revealed that a maternal bud forms upto 15 filial ones, some of which remain open. The state duration is above 10-12 years.

In the old generarive state, perennial orthotropic SA dies in the bush central part. New SFs appear utmost rare. The orthotropic SA number in the bush does not exceed 10, their length is $90-120 \mathrm{~cm}$. Only generative shoots with bracteose inflorescence are developed on SAs, forming frondose shoots is unusual. As a result of aging, lateral FSs are not formed in the orthotropic SA lower part. The preserved lateral buds on axis are not able to branch, but fully realized ones die off. Xylopodium is $12.0 \mathrm{~cm}$ in diameter, cracked and carried a large number of stumps of the dead shoot systems. The state duration ranges from 5 to 6 years.

The post-generative specimens are low plants with forming vegetative shoots of preserved xylopodium and SA buds. In the bush structure, there are 3-7 dying SAs of 50-75 $\mathrm{cm}$ height. The main root is preserved during the whole specimen ontogenesis. The state duration does not exceed 3-4 years.

The subordinate structural elements of adult M. bracteata specimens have been revealed using the architectural analysis: a Module - a branched monopodial perennial axis with deterministic growth at a growth unit, spiral phyllotaxis and radial symmetry. Its apical bud dies off without forming an inflorescence. A lateral perennial skewed orthotropic shoot is formed of a resting bud in the module middle part, which structurally identical to the main, but smaller. Annually dying lateral shoots are formed of branching resting buds on that perennial shoots, their apical meristem differentiates/not differentiates into an inflorescence. The architectural unit of M. bracteata consists of 5 categories of axes: 1 perennial orthotropic, 2 - perennial lateral skewed orthotropic, 3 - annual lateral generative bracteose, 4 - annual lateral generative frondose, 5 - annual lateral vegetative ones.

\section{Conclusions}

Thus, the ontogenesis of $M$. bracteata specimens, studied in the conditions of East Kazakhstan, is complete, includes two phases of morphrogenesis: primary shoot, primary bush. The total duration of ontogenesis does not exceed 35 years. The adult bush structure is built due to perennial orthotropic and skewed orthotropic SA development. The architecture unit consists of five subordinate axes: the main and lateral formed as a result of delayed mesotonic lateral branching.

Work is carried out in frames of the projects of the state mission of the Central Siberian Botanical Garden of SB RAS № AAAA-A17-117012610053-9 and № AAAA-A17-117012610054-6.

\section{References}

1. M. T. Mazurenko, Biol. Inland Waters, 3 (2001)

2. E. M. Lyakh, A. Yu. Astashenkov. BIO Web Conf., 16 (2019).

3. I. G. Serebryakov, Ecologic plant morphology (Moscow, 1962) 
4. D. Barthélémy, Y. Caraglio, Ann.of bot., 99, 3 (2007)

5. E. G. Bobrov, Bot. J. 52, 7 (1967)

5. T. A. Rabotnov,Tr. BIN AN USSR. Geobot., Ser. 3 (1950)

6. A. A. Uranov, Sci. Rep. High. Schools. Biol. Sci., 2 (1975)

7. A. A. Uranov, T. I. Serebryakova (eds.) Cenopopulations of plants (basic concepts and structure (Moscow, 1976)

8. M. T. Mazurenko, A. P. Khochryakov. Structure and morphogenesis of shrubs (Moscow, 1977)

9. E. M. Lyakh, Bull. Main Bot. Gar. 4, 13-16 (2012) 